\title{
The motives for cooperation in work organizations
}

\author{
HELENA LOPES* \\ ISCTE and DINÂMIA, Research Centre on Socioeconomic Change, Lisbon, Portugal \\ ANA C. SANTOS \\ Centre for Social Studies (CES), Coimbra, Portugal \\ NUNO TELES \\ DINÂMIA, Research Centre on Socioeconomic Change, Lisbon, Portugal
}

\begin{abstract}
This paper aims to contribute to a better understanding of cooperation in productive ventures, conceived of as collective action endeavours that require cooperation rather than mere coordination. It is argued that cooperative behaviour is grounded on three kinds of 'common goods', defined as goods that are shared and recognized as beneficial by the workers. These comprise common goals, relational satisfaction, and moral norms and values. The commonly held goods are associated with motives and behavioural rules which constitute both the reasons for cooperating and the means through which the dilemmatic nature of cooperation is overcome. It is further argued that the binding character of these rules is closely linked to humans' ability and opportunity to communicate. Normative guidelines relative to management practices and directions for future research are also derived.
\end{abstract}

\section{Introduction}

Organizing production in collective settings allows people to achieve collectively, through cooperation, what they cannot achieve individually. But cooperation can be problematic if cooperative effort is costly to monitor by the employer or by fellow workers. Collective action then acquires a social dilemmatic nature in that every worker would be better off if all cooperated, but each worker finds in his narrow self-interest to shirk on his production effort (Olson, 1971).

Nonetheless, cooperation is a prevailing feature of agents' behaviour in working environments. Every organization depends daily on a multitude of acts of voluntary contribution to common goals and solidarity. This kind of behaviour has been integrated in economic theory either by accepting it as a

*Email: Helena.lopes@iscte.pt

The authors are indebted to three anonymous referees for very valuable comments and suggestions. Any remaining errors are ours. This paper was partially funded by DIME (Dynamics of Institutions and Markets in Europe) - EU 6th Framework Programme. 
default behavioural assumption (in evolutionary economics and the knowledgebased theories of the firm, for instance) or by making it part of agent's preferences - e.g. reciprocal behaviour is taken as the expression of a preference for cooperating (Rob and Zemsky, 2002; Bewley, 1995; Fehr and Gächter, 2000; Fehr and Falk, 2002). The motives for cooperation presented in economic literature typically assume an individualistic character and it does not explore the normative impact of cooperation on organizations' governance.

This paper aims to contribute to a better understanding of cooperation in the workplace by stressing the role of the pursuit of common (rather than individual) goals and the endorsement of shared motives in supporting cooperation. It does so, first, by identifying the kind of motives that favours voluntary effort and, second, by pinpointing the kind of institutional arrangements that may promote and sustain cooperation. It is argued that cooperative behaviour is grounded on various kinds of 'common goods', defined here as goods that are shared and recognized as beneficial by those taking part in the cooperative endeavour.

The paper is structured as follows. In the next section, the nature of the collective action problem and the solutions put forward by organizational economics are examined. It is noted that all strands of literature now acknowledge that some kind of norm-governed behaviour is required for the effective exercise of cooperation. The third section introduces the notion of 'common good'. Section 4 defines the three kinds of common goods pursued by workers and the sets of motives that are prevalent in the pursuit of each kind. Section 5 elaborates on the structure of commitment and highlights the role of communication to the effective exercise of cooperation. Normative guidelines relative to management and organizational governance are derived in the sixth section of the paper. The last section concludes with the suggestion of some directions for future research.

\section{The dilemmatic nature of collective action}

When information is perfect, costless coordination can be guaranteed by market mechanisms. Under such circumstances, every agent knows how others are going to behave and also knows how to behave himself. But coordination cannot be taken for granted when information is imperfect or costly. The focus then shifts from the study of competitive markets to firms and other forms of organizing production. The behaviour of other individuals can no longer be anticipated: 'Tactics, strategy, guile and opportunism become viable behavior traits and so do countervailing traits of honesty, openness, trust and reputation ... This gives rise to relational behavior problems that cannot exist within the neoclassical framework' (Demsetz, 1995: 35, author's italics). Cooperative behaviour cannot be taken for granted, not even when it would be in the interest of all concerned (Olson, 1971). 
Any production activity can be conceived of as a collective action endeavour that requires cooperation rather than mere coordination. Organizations are, indeed, 'systems of cooperative services of persons' rather than the sum of services provided by individuals (Barnard, 1938). Team production is the most obvious instance of cooperative endeavour, but production that is not organized in teams can also have a collective action dimension if there is interdependence between workers. In collective production settings, workers cannot define their effort levels solely in terms of their own preferences, they must also consider other workers' behaviour. The implication of the nonseparability of choice of effort is that expectations about others' behaviour matter. And when, as game theory has shown, the action of one agent is conditional or contingent on expectations about the actions of others, multiple outcomes are possible at varying levels of effort, including both joint cooperation and defection. From this, it follows that the solution to the collective action problem ultimately hinges on assuring that others will cooperate too. ${ }^{1}$

Collective action, as Elster put it, can be conceived of as 'the choice by all or most individuals of the course of action that, when chosen by all or most individuals, leads to the collectively best outcome' (1985: 137). Collective action, or cooperation, calls for intentional and voluntary contribution on the part of each participant. This is all the more required by the increasing complexity and knowledge-intensive character of present production processes, which (a) require firm-specific individual skills, (b) are difficult to monitor and control, (c) demand a high degree of worker interdependence and cooperation, and $(\mathrm{d})$ result in a high degree of role and task ambiguity. If co-ordination (i.e., ordering together) sufficed to organize separate and well-defined tasks and activities, cooperation (i.e., operating together) is called for when uncertainty and interdependence increase. It is no longer a matter of just bettering the circulation of information, orders, and messages. Working together, in the modern production conditions, requires a common understanding and the establishment of robust agreements on the nature of the problems to be solved and the knowledge to be developed, the definition and evaluation of the objectives to be achieved, and the subjective commitment of the individuals involved.

Two kinds of solutions to the collective action problem in firms have been put forward - one is based on pecuniary incentives, while the other recognizes the need for organizational arrangements and directed coordination. Alchian and Demsetz, the first proponents of an incentive-based solution, argued that firms exist precisely because they 'resolve the shirking-information problem of team production better than does the non-centralized contractual arrangement' (1972: 783). In firms, a 'centralized contractual agent' (the employer) monitors the 'owners of cooperative inputs' (the workers) and meters the contribution of 
each agent. He then establishes rewards that are closely tied to effort, which ensures workers' effort and prevents shirking. The monitor is himself deterred from shirking by receiving 'residual rewards'. ${ }^{2}$ By aligning the workers' and the organization's interests, the performance-based incentives render behaviour more predictable. The Agency and New Property Rights Theories (e.g. Jensen and Meckling, 1976; Grossman and Hart, 1986) took this line of reasoning further by selecting incentive-compatible devices and the allocation of property rights as the main instruments to ensure cooperation in firms.

A second strand of literature, pioneered by Coase (1937), upholds that directed rather than price-guided coordination constitutes the essence of firms and other organizations. Transaction cost theories also accept that organizations come into existence because of incomplete and asymmetric information, which gives rise to agency issues. But uncertainty in the formulation, monitoring, and enforcement of contracts is to be solved via structured hierarchical forms. Shirking within the organization is tackled by putting workers under the direct control of a third party, who monitors their behaviour and ensures compliance with the explicit and implicit orders and agreements. On this view, the design of incentivecompatible devices does not obviate the need for direction. Cooperation requires the design of appropriate institutional arrangements, which are grounded in more or less formal lines of authority.

Authority is the character of a communication (order) in a formal organization by virtue of which it is accepted by a contributor or 'member' of the organization as governing the action he contributes; that is, as governing or determining what he does or he is not to do ... According to this definition, authority involves two aspects: first, the subjective, the personal, the accepting of a communication as authoritative; and, second, the objective aspect - the character in the communication by virtue of which it is accepted, the 'system of coordination'. (Barnard, 1938:163, authors' italics)

Authority ${ }^{3}$ appears as a key factor for cooperation, but its effectiveness cannot be taken for granted; it always rests on the acceptance or consent of the persons to whom it is addressed and it does not reside in those who issue the orders. But what is it that explains individual willingness to obey orders or undertake tasks which conflict with their preferences? Obedience alone does not suffice to ensure and account for cooperation in work organizations, as workers will always have considerable latitude to determine the extent and nature of the effort provided (Lopes and Caldas, 2008).

2 Efficient coordination, and even cooperation, is ensured through a Hobbesian contract since the general consent on contracting a Leviathan is deemed to solve workers' shirking.

3 It seems that Barnard's 'lines of authority' means both authority and hierarchy, a term that never appears in Barnard's book. Barnard, like Arrow, Williamson and others, does not clearly distinguish between hierarchy and authority, though he carefully differentiates objective authority - defined as authority of position - from authority of leadership - defined as personal ability (Barnard, 1938: 173). 
A third strand of literature, the knowledge-based and evolutionary theories of the firm (Nelson and Winter, 1982; Nonaka et al., 2000), shifts the theoretical focus. The firm is now taken as a collective action device that develops and processes knowledge in order to create specific, idiosyncratic, competences. Rather than being an answer to an agency problem, the firm is now a response to a collective cognitive problem. Cooperation between individuals is taken for granted and it is achieved by cognitive routines: 'what is central to coordination is that individual members, knowing their jobs, correctly interpret and respond to messages they receive' (Nelson and Winter, 1982: 127). Routines are stable sequences of interactions that coordinate the organization's learning and production processes. The predictability of routines reduces fundamental uncertainty and replication of (tacit and codified) knowledge is guaranteed (Becker, 2004). By their repetitive and permanent character, routines also enable some sort of unconscious acceptance of rules, thus preventing potential conflicts. The cooperation dilemma is thus solved by the absence of agency. Routines play the deus ex machina role inside organizations.

In the last two decades, all three strands of literature implicitly recognized the insufficiency of their previous accounts of cooperation and devoted increasing attention to reciprocity, trust, and reputation, which are deemed essential for achieving efficient organizational coordination. Trust reduces transaction costs, helps enforce incomplete contracts, lessens the hold-up problem related to asset specificity, and so forth. Assuming a functionalist viewpoint, the organizational economics literature conceives trust and reciprocity as instrumental norms, resulting from calculated (long-term) self-interest and not intrinsically valued. Insofar as both firms and employees have interest in a long-term relationship, workers voluntarily agree to act in accordance with the organizational goals if treated fairly; the firm has, in turn, no incentive to take advantage of workers if workers' performance is satisfactory. It is therefore in each party's interest to build a reputation for honesty, for being trustworthy and cooperative. Adherence is automatic as long as norm compliance is in the agent's interest. Indeed, the formal models of bilateral reciprocity and multilateral trust-reputation show that spontaneous cooperative equilibria are rationally sustainable (Baron and Kreps, 1999).

But it must be noted that the conditions required to ensure that the value of reputation exceeds the gain from cheating are very demanding: the horizon over which the interaction is expected to continue must have no known end; interaction must involve the same agents; and the information which is necessary for identifying and penalizing past cheaters must be easily disseminated. The solutions based on compliance with social norms for instrumental and self-interest reasons cannot fully account for cooperation within real-world organizations. In order to understand cooperation one must go beyond the methodological individualistic framework of neoclassical economic theory with its focus on utility-maximization as the main explanatory principle of 
human action. The notion of common goods introduces additional motives for cooperation that go beyond individual interest and point to commonly held and valued elements.

\section{Cooperation and the common goods}

The utility principle is contaminated by three problems that are particularly critical to the analysis of cooperation. Firstly, it does not say anything about what is maximized. ${ }^{4}$ Secondly, it lumps together, in the utility function, the various motives that people pursue while cooperating (Akerlof, 1982; Fehr and Gächter, 2000; Rob and Zemsky, 2002). ${ }^{5}$ Thirdly, it only acknowledges individual motives for action.

We introduce the notion of 'common goods' to account for the emergence and sustainability of cooperation in collective endeavours. The reason is that understanding collective action must necessarily evoke commonly held 'goods' that transcend the particular individuals concerned. Thus, and in contrast to standard economic theory that focusses exclusively on the private-good components of actions, the notion of 'common goods' aims at highlighting the shared-benefit components of actions. The term common good has been widely discussed in philosophy, ethics, political science, and economics (Walzer, 1983; Lutz, 1999). Different definitions have been proposed and various meanings have been attached to it. But they all refer to a good that is shared and recognized as beneficial to the members of a given community. The definition of common goods adopted here extends the notion of a good to encompass all entities that are capable of satisfying human wants and needs (including ends, relations, and values).

The notion of common goods highlights two basic aspects inherent to collective action. Firstly, and in contrast to the individualist orthodox economic theory, in which individuals are solely guided by private wants, the notion of common goods is meant to emphasize the fact that individuals involved in a collective endeavour may share common ends and needs which are collectively valued by the members of the group. Secondly, the notion of common goods is also meant to highlight the importance of the process of collective action itself, the value of which goes beyond its instrumental contribution to the commonly

\footnotetext{
4 This is known as the substantiation issue. Unveiling the content or substance of the principle of utility violates the normative neutrality of standard economics. There has been, in the history of economic thought, various and successful attempts to free economics from any substantial statement on what preferences are pursued by economic agents and, indeed, of the concept of utility itself (Pareto, 1968[1909]; Samuelson, 1938). Recent theoretical and empirical developments, however, have increasingly injected substance into the utility principle.

5 Rob and Zemsky (2002), for instance, introduce the notion of a 'preference for cooperating', distinguishing 'intrinsic utility', which is derived from cooperative tasks, from 'utility from compensation', which is provided by other kind of tasks, without further inquiring into the implications of the distinction.
} 
held ends. In what follows particular attention will be given to the personal and social relations that people enter into when doing something together. Personal interactions result in the creation of outputs of a communicative or relational nature. As will be shown, these outputs are common goods as they can be valued by each member along with other type of goods. This is not to deny that participants, besides having a common interest in cooperation, may also have conflicting objectives as well, as they may evaluate differently the co-produced and co-consumed relational goods.

To sum up, the notion of common goods endorsed here emphasizes the social constitution of individuals and their embeddedness in a web of social relations. Individuals qua social beings possess a special consciousness of the feelings, beliefs, and purposes which are shared with those with whom they come into contact. This consciousness leads to setting aside the narrower self and conforming to social and moral codes.

\section{Cooperation and the common goods pursued in work organizations}

We have seen that self-interest alone does not guarantee cooperation even when it is in individuals' interest to do so. We have further argued that common rather than individual entities must be introduced to explain cooperative behavior. In this section, we identify three common goods that support cooperative behaviour and the sets of motives and behavioural rules that are prevalent in the pursuit of each kind.

That the resolution of collective action problems must evoke different sets of motives and rules of behaviour other than self-interest and rational calculation has already been noted. Amartya Sen (1973, 1977), for instance, distinguishes three different motives for action - self-interest, sympathy, and commitment and two behavioural rules - pursuit of one's welfare (which is a function of both self-interest and sympathy) and moral rules. Sen also highlights the role of moral rules in solving social dilemmatic situations by 'demanding suspension of calculations geared to individual rationality' (1973: 250). Thus, in Sen's view 'it is action based on commitment rather than sympathy which would be nonegoistic' (1977: 31) and crucial to enforce social contracts.

The analytical framework put forward in this section follows Sen's demarcation but the three motives for action are now taken as commonly rather than individually held. It is argued that any collective endeavour involves three common goods - the pursuit of a common goal, relational satisfaction, and commitment to social and moral norms and values. A direct link is then forged between the three kinds of common goods, the underlying motives, and the behavioural rules that together ensure cooperative action. The upshot is that the three commonly held goods constitute the motives for cooperating and therefore provide an account of why individuals cooperate. The two last goods - relational satisfaction and commitment to social and moral values - besides constituting 
ends of action, evoke particular norms of conduct that are to guide action and therefore provide a comprehensive account of how cooperation is achieved in collective endeavours.

\section{Common goal}

The first common good is the pursuit of a particular common goal: the productive endeavour that brings the workers together. The common goal is here defined as a commonly desired state of affairs that cooperation brings about. Because cooperation generates a cooperative surplus, the common goal is a common good that transcends the individuals concerned, despite the fact that it is individually recognized as beneficial. This is the weakest sense of the common good since cooperation is obtained through the alignment of individual interests. However, the workers contribute to the pursuit of this common good if and when they expect others to contribute too; that is, workers will be willing to do their part if they expect that all, or enough others, will do their part too. The common goal must be perceived as a common good by the members of the group for cooperative action to take place. In this view, then, cooperation is obtained via a kind of enlightened self-interest, insofar as individuals perceive cooperating as a common good, rather than via the satisfaction of specific preferences, as it is depicted in some social preferences models. Having perceived cooperating as a common good, that is, as being commonly shared and recognized as beneficial to all, workers act 'as if' they were pursuing the common goal, even if in fact they are only interested in their own welfare. ${ }^{6}$ But this notion of 'self-interest' is sharply distinct from the individualistic account since it presupposes both the presence and the perception of a common and shared goal.

In work organizations, most workers provide effort because it is rewarded with a monetary compensation that allows them to derive utility from consumption. ${ }^{7}$ The pursuit of the first common good is therefore instrumental; it is a means to an end regardless of the relationship with others. The behavioural rule related to this common good is still the pursuit of self-interest, but this notion of selfinterest departs from the one endorsed by rational choice theory. Individuals are now willing to give up cheating or exploiting cooperative partners. ${ }^{8}$ It can then be said that the first common good considers agents as 'separative' but not isolated selves. They are autonomous and self-interested human beings

6 We could of course assume that workers do intentionally pursue common (instead of individual) goals, but this would amount to assuming what is to be explained. (We do not explore in this paper the notions of identification with a group or collective intentionality, which constitute alternative, even if possibly related, accounts of cooperation).

7 The first common good therefore maintains a typical presumption of neoclassical theory and the theory of the firm: the demarcation between consumption and production in that consumption takes place exclusively outside the organizations and no utility is derived from work (see Demsetz, 1995).

8 The agents can be said to hold assurance-game preferences, as noted by an anonymous referee, who we thank. 
who engage in instrumental exchanges with others (cf. Nelson, 2001). The predominant value ruling behaviour is economic freedom, freedom from personal ties and obligations to others, and freedom to disregard others' desires and value judgements. Social relations are impersonal, they focus on wants rather than needs, and dissatisfaction is expressed by 'exit' rather than 'voice' (Anderson, 1990).

That the common goal is beneficial to all and that workers might be predisposed to do their part if significant others do theirs do not guarantee cooperation. Workers must also expect others to forgo the egoistic pursuit of benefit and to abide by social norms. Only then can the dilemmatic nature of collective action be removed. We argue in the following sections that such expectations and abidance to social norms derive from and are supported by two additional kinds of common goods.

\section{Relational satisfaction}

The second common good pursued in collective action is relational satisfaction. Besides the achievement of the common goal, collective action also contributes to the fulfilment of gregariousness and the human need for affiliation; that is, besides the instrumental value, collective action has also an intrinsic value. We follow closely Gui's (2000, 2005) account of 'interpersonal interactions' and Sugden's (2005) elaboration of 'fellow-feeling' to explain how individuals' affective needs promote and sustain collective action.

Interpersonal interactions rather than consisting in 'a set of transfers ... of entities which pre-exist the interaction itself and are possessed by either party', consist instead of 'a process that combines individual contributions into the creation of peculiar outputs of a communicative/affective nature: relational goods' (Gui, 2005: 152). Relational goods are then the affective and communicative components of interpersonal relations that are valued by the participants and confer wellbeing. The affective states generated by these interactions result from actors' consciousness of one another as particular human beings. Relational goods are outputs of personal interactions in which the interactants act as both producers and consumers. ${ }^{9}$ Illustrations of such goods are, for instance, friendship, conviviality, and solidarity. Relational satisfaction is thus an intangible good of a communicative or affective nature that is jointly created and enjoyed by the relation with one another.

Drawing on Smith's Theory of Moral Sentiments, Sugden (2005) identifies two basic mechanisms at work in the production of relational satisfaction. The

\footnotetext{
9 The use of the notion of 'consumption' might be problematic here. On the one hand, it may seem legitimate for it refers to the satisfaction derived from relational goods. But, on the other hand, we cannot properly speak of consumption because the (relational) good does not disappear with its use. It may instead produce other goods. The use of the term 'investment' in connection to relational goods might be ambiguous too. Relational goods are not resources likely to yield future returns, they are valued in themselves instead.
} 
first one is the human capacity for fellow-feeling: 'one person B's fellow-feeling for another person A is to be understood as B's lively consciousness of some affective state of A's, such that B's consciousness has similar affective qualities to A's state' (56). This mechanism requires cognitive elements as well as affective ones. It involves the capacity of perspective taking, that is the ability to put oneself in somebody else's shoes. The second mechanism is the human capacity for taking pleasure in the correspondence of sentiments: 'whenever one person $\mathrm{A}$ is conscious of a correspondence between his own affective response to some state of affairs and the response of another person B, that consciousness in itself has positive affective quality for A. Conversely, if $\mathrm{A}$ is conscious of dissonance between his response and B's, that consciousness has a negative affective quality for A' (58). Sugden then explains relational satisfaction as arising from both mechanisms.

What Gui and Sugden do not point out is that relational satisfaction is not only an (inter)individual good, it is also a common good. And this is so because of two main features. Firstly, the valuation of personal relations depends on whether people with whom one is interacting are valuing them too. Secondly, relational satisfaction is jointly produced and consumed. Thus, and in contrast to the autonomy and independence involved with the consumption of private goods, which are solitary goods, i.e. goods whose value does not depend on whether other people also value them (Sunstein and Ullman-Margalit, 2001), relational goods cannot be enjoyed by isolated individuals. The utility derived by relational goods stems precisely from the shared-benefit components of actions. The strict separation between private and common goods hence breaks down. Relational satisfaction is a good because it is commonly shared. The second common good thereby replaces the conception of individuals as 'separative selves' by a model of 'individuals-in-relation' (Nelson, 2001).

The psychological dispositions of fellow-feeling and the correspondence of sentiments are linked to those of approval and disapproval. The capacity to take the perspective of the other and of sharing their feelings is the basis for judgments of approval and disapproval of own and others' behaviour. Indeed, one approves (disapproves) of somebody's (own) actions when one sympathizes (does not sympathies) with his (own) feelings. These judgments are in turn critical to the enforcement of norms of conduct. On the one hand, they contribute to form expectations of the way in which it is appropriate to behave. On the other hand, individuals derive pleasure when their actions are approved by others and discomfort otherwise.

Hence, and notwithstanding the personal costs involved in the provision of effort, workers may adhere to cooperative norms driven by the pleasure they derive with the correspondence of sentiments of approval and/or by the pain they anticipate if they do not abide by the salient norm of conduct. In case of conflict, individuals even revise their 'preferences' so as to align their sentiments to those of others. The focus on this second common good therefore 
highlights the endogeneity of 'preferences'. Preferences are endogenous because they are amenable to the influence of the relational goods produced in collective endeavours.

Relational satisfaction is at the basis of a large set of behavioural norms and values, such as trust, reciprocity, loyalty, and respect, which are essential for the quality of personal interactions. The norms governing reciprocity differ from the norms of strict contractual exchange (Akerlof, 1982). While the latter are impersonal, the former are personal because their goal is precisely to affirm and perpetuate the ties that bind the donor and the recipient and they involve taking into account others' welfare and value judgements.

The shortcomings of this common good are twofold. First, relational satisfaction is vulnerable to the motives, expectations, and beliefs of the group members. When expectations are not met, the provision of this good may be in danger. Second, there is the risk of this common good turning into a social bad. The nurturing of gratifying personal relations tends to create a strong group identity, which may have as a corollary the exclusion of outsiders. Hence, while recognizing that relational satisfaction favours willingness to cooperate, it carries risks that call for broader senses of membership, common ends, and norms of conduct.

\section{Moral norms and values}

We have seen that the psychological dispositions of fellow-feeling and correspondence of sentiments are critical to create and sustain social and moral norms. People desire others' (and their own) approval and fear others' (and their own) disapproval which lead them to endorse and abide by particular norms of conduct, among which stand moral norms. ${ }^{10}$

Moral norms are common goods too. Similar to relational satisfaction, the value of moral norms depends on them being commonly shared and valued. Their normative strength derives precisely from the individual consciousness that a given norm is shared with others. But in contrast to relational satisfaction, moral norms and values involve impersonal valuations. Their normative force does not depend on the particular individuals one interacts with. Moral norms provide reasons for acting that go beyond the particular circumstances and the particular persons involved. Moral norms and virtues can then be regarded as universal in the sense that they entail our actions toward all others (the 'distant' others), rather than only towards particular individuals (the 'near' others). While relational goods were characterized as goods individually and commonly held by the members of a given community, moral norms and values actually exist beyond the interacting individuals. Unlike relational goods, which solely exist

10 We do not pretend here to settle the widely discussed issue of the source of morality (evolutionary biology, social conditioning, cognitive and moral development, transcendental endowment, etc.). It suffices for our purpose to evoke the ability and the need for sympathy. 
within the interactions themselves, moral norms and values have an existence of their own. ${ }^{11}$ They constitute mutually expected norms of conduct that drive and stand above individuals' actions, even if their appropriateness in a given circumstance is always subject to interpretation.

Moral norms and values promote cooperation by prescribing actions that may entail self-sacrifice and personal costs for the benefit of others. This idea is conveyed in Sen's notion of commitment. If social preferences and relational satisfaction may, as some have argued, be part of a broad definition of selfinterest since they provide psychological or emotional 'utility' (Sen, 1977; Fehr and Gächter, 1998), commitments unequivocally depart from the reference to individual welfare. As Sen has put it, 'one way of defining commitment is in terms of a person choosing an act that he believes will yield a lower level of personal welfare to him than an alternative that is also available to him'. Thus, 'the action is really chosen out of the sense of duty rather than just to avoid the illfare resulting from remorse that would occur if one were to act otherwise' (32). This is in fact the second main difference between social and moral norms and the second and third common good. Whereas conformity to a given social norm may be induced by avoiding the psychological cost of falling pray to social sanctioning, conformity to moral norms is first and foremost informed by a sense of duty. When considering that the social preferences models try to depict behaviour by utility functions that lump together different kinds of motives the very proponents of this approach conclude that there 'remain legitimate doubts whether [social preference] models capture the phenomenon of reciprocal fairness in a fully satisfactory way' (Falk et al., 2003: 3).

Distinguishing behaviour led by social norms from behaviour led by moral norms is, however, not clear cut. As mentioned above, both kinds of norms may be seen to emerge and be sustained by interpersonal relations. Moreover, conformity to social norms may be partially grounded on moral norms; in the case of trust, for instance. Trusting that others will comply with previous agreements, even when it goes against one's self-interest, may be backed by one's adherence to a moral code rather than by enlightened self-interest or the desire for relational satisfaction. Individuals actually follow particular norms of fairness even when they do not have the opportunity to develop relational ties or establish reputation for future beneficial interactions. The fact that third parties are sometimes willing to punish, at a cost to themselves, non-cooperative behaviour that affects others may be an indication of just that (Fehr and Fischbacher, 2003). At any rate, moral norms are distinct from social norms in that their underlying motivation is the sense of duty, and conformity is not contingent on other people's behaviour. Workers, or a substantive number of them, provide effort if they take it as a moral duty. In an extensive US survey, moral motivations

11 That is why moral norms and values can be and are most often viewed as 'institutions', while relational goods cannot have this theoretical status. 
appear as the most important motivations to work hard; they are followed by positive intrinsic motivations, peer pressure, and only then positive incentives (Minkler, 2004: 875).

Relational and moral goods are intrinsically related: no relational satisfaction will ever be sustained without morally driven behaviour. However, as argued, relational and moral goods are of a deeply different nature and moral norms constitute a motive for action for their own sake - though duty may less powerfully drive action because it is only indirectly linked to desire (see section below).

To conclude, the view endorsed here is that cooperative behaviour in work organizations is supported by three common goods that are shared and recognized as beneficial by the workers. The main results of the analysis carried out is synthesized in Table 1.

\section{Beyond the instrumental nature of cooperation: commitment and communication}

When action is driven by the pursuit of self-interest, participants, who may well be silent, focus on the success of their own endeavour. Under these circumstances, the prospects for cooperation depend on the convergence of the various interests in presence. In the previous section, we argued that cooperation may be motivated by the existence of a common goal but that it also requires abiding by social and moral norms. In this section, we further explore the structure of commitment, namely its normative character, and the role of communication in cooperation.

The New institutional literature conceives all kinds of rules and norms as 'contracts', that is agreements resulting from voluntary bargaining between individuals mainly motivated by enlightened self-interest. The importance of a common normative background for cooperation is acknowledged by organizational economists in the following terms:

Firms are riddled with relational contracts: informal agreements and unwritten codes of conduct that powerfully affect the behaviours of individuals within firms. There are often informal quid pro quos between coworkers, as well as unwritten understandings between bosses and subordinates about taskassignment, promotion, and termination decisions. (Baker et al., 2002: 39, our italics)

For Baker et al. these informal agreements are 'sustained by the value of future relationships' (2002: 39), i.e. they entail an exclusively instrumental character (corresponding to the first common good). The viewpoint defended here, however, is that these 'informal agreements' entail also a non-instrumental character. When considering that contracts consist by and large in the trading of promises, one necessarily concludes, as Durkheim (1984:158) did, that 'in 
Table 1. Common goods, related motives, and rules

\begin{tabular}{|c|c|c|c|c|}
\hline Common goods & Motive and type of valuation & Behavioural rules & Type of interaction & Predominant values \\
\hline Common Goal & $\begin{array}{l}\text { Enlightened self-interest: the } \\
\text { good is perceived as being } \\
\text { commonly valued }\end{array}$ & Satisfying individual welfare & Impersonal/ individualistic & $\begin{array}{l}\text { Freedom from ties / } \\
\text { obligations }\end{array}$ \\
\hline $\begin{array}{l}\text { Relational } \\
\text { satisfaction }\end{array}$ & $\begin{array}{l}\text { Sympathy: valuation of the } \\
\text { good depends on others' } \\
\text { (personal) valuation }\end{array}$ & $\begin{array}{l}\text { Social norms: individual } \\
\text { welfare depends on others' } \\
\text { welfare and actions }\end{array}$ & $\begin{array}{l}\text { Personal/ the good lies in } \\
\text { the relationship }\end{array}$ & $\begin{array}{l}\text { Trust, loyalty, } \\
\text { reciprocity }\end{array}$ \\
\hline $\begin{array}{l}\text { Moral norms and } \\
\text { values }\end{array}$ & $\begin{array}{l}\text { Good commonly valued but } \\
\text { impersonal valuation }\end{array}$ & Commitment & Impersonal/ universal & Justice, fairness \\
\hline
\end{tabular}


a contract not everything is contractual'. Contracts are never strictly bilateral, they are mediated by binding moral rules that partly transcend the particular individuals involved (the third common good).

For Searle (2001), language has a fundamental role in binding individuals to previous agreements. Through the use of language, humans intentionally and rationally commit themselves to some specific voluntary action to be carried out in the future, regardless of what their other motivations might be when the time comes (Searle, 2001). Commitments thus create desire-independent reasons for action. Making a promise to help a colleague creates a desire-independent reason for action. Helping the colleague is not motivated by the desire to help, but instead by the commitment to help which is independent of one's desire or preference at the moment. Commitments are created with the use of language by means of some 'semantical categorical imperative' (Searle, 2001). Human societies require a deontology and it is language that provides the means for it: 'No language, no deontology' (Searle, 2005: 14). Language and behavioural rules carry a deontology, i.e. a set of rights, duties, obligations, and responsibilities that constitutes 'the glue that holds society together' (Searle, 2005: 9-10). ${ }^{12}$

The neglect of the role played by communication might explain the difficulty of standard economics in acknowledging and accounting for behaviour driven by moral motives. In fact, Hobbes' famous claim still informs most theoretical work in economics (including the social preferences approach): 'Covenants without the Sword are but Words, and of no strength to secure a man at all' (Hobbes, 1968: 223). However, a significant amount of experimental work has already showed that communication in collective action is not mere 'cheap talk' (Ledyard 1995). It is, in fact, the most effective device in sustaining high levels cooperation in one-shot as well as in repeated public good games (Sally, 1995; Ostrom, 2007). Communication epitomizes three key aspects of cooperation: (i) to agree, (ii) with someone, (iii) about something.

Rather than being conceived as 'strategic action', i.e. action solely guided by individual interest and focused on the action's outcome, cooperation in organizations should be regarded as involving also 'communicative action', as Habermas (1984) defines it - actions that result from participants' agreements. While strategic (and instrumental) action consists in determining the best means to reach a particular end, communicative action aims at focusing participants' attention on the definition of common ends. In communicative action, people are treated as ends and not as means, and language is used with the truthful desire to achieve an agreement. ${ }^{13}$ Language is also used in strategic action to coordinate plans of action or to persuade workers to share the organization's

12 The same idea is expressed by Elster (1985: 142): 'Duty may be the cement of society.'

13 One may rightly object that communicative action demands that individuals are free and independent, which is not the case in most work organizations where workers depend on the organization for their living. Though, there is always some room for cooperation and communicative action in work organizations. 
goals, for instance. Conversely, in communicative action, communication aims at jointly discussing the results, the goals, or the means to be collectively pursued or undertaken. Its aim is to establish a dialogue and common understandings of the situation at hand. What Habermas (1984) stresses is that communicative action must be grounded on the existence of shared values if individuals are to bypass their self-centred preferences. The actual coming together and reaching agreement through inter-understanding processes allow the identification of shared goals and their effective pursuit. ${ }^{14}$ While strategic action presupposes stable and fixed preferences and obligations, communicative action assumes instead that 'preferences' and the 'rules of the game' are identified and construed through communication (Habermas, 1973).

We have argued that the normative nature of the third common good is closely related to language. Besides strategy, cooperation necessarily entails communicative action, which in turn requires a common normative background, which is the existence of the third common good. The type and quality of communication within work organizations hence crucially determine the extent and effectiveness of cooperation.

The importance of communication for cooperation is enhanced by the fact that what constitutes cooperative behaviour in any particular case is ambiguous. Formal rules and agreements do never provide a precise description of the desired behaviour; they are too general and abstract since they are supposed to guide behaviour in a range of related but differentiated situations. Thus, even though rules and norms confer some degree of predictability to human behaviour, they do not dictate it. The same rule may give rise to quite different behaviours and a given behaviour may be subject to diverse interpretations. Misunderstandings necessarily occur in a world populated by boundedly rational agents endowed with incomplete information about other agents' intentions and choices. But these misunderstandings might be overcome by communication taking place in the particular context of interaction. Communication allows the signalling of intentions and the expressing of commitments that are crucial for cooperation.

Actions driven by social and moral norms may be subject to misunderstandings that call for justification. Communicative action gives the possibility to justify one's action by having recourse to shared norms and values. One may justify an action by revealing the (moral) norm that constituted the reason for such action. The good or right action in a particular social dilemmatic situation can hence be discovered: a reason for acting would be good or just if it is accepted(able) by others as such. Justifications must be able to withstand public scrutiny by reasonable persons. The reference to shared norms and values, that is

14 This is consistent with Ostrom (2000: 254) findings: '[o]nce communication is allowed, subjects [in controlled laboratory settings] spend time and effort assessing each other's trustworthiness and reaching agreements about the best strategies they should jointly take'. 
the reference to publicly and commonly acceptable reasons for action is required if cooperation is to be sustained. This is precisely what marks the difference between norms or values and preferences or tastes: only the former are amenable to collective and rational discussion.

To sum up, cooperation might be initiated because a worker's interest happens to converge with another's or because he/she seeks for relational satisfaction the first and second common goods - but the cooperative process will call for other motives for action. In all cooperative processes, commitments are taken that subsequently constitute reasons for action. Furthermore, in cases of misunderstandings or conflicts, reasons other than the pursuit of self-interest will have to be invoked if the cooperative process is to continue. Together, the three common goods constitute the common ground that contributes both to motivate and sustain cooperation.

\section{Implications for management}

Conflicts naturally arise between the various motives and goals present in each organization. Cyert and March (1963) conceived the organization as a 'coalition' of different agents pursuing divergent goals where the 'quasi-resolution of conflicts' are achieved through bargaining. In our perspective, conflicts might be quasi-resolved by a more or less public justification of actions, which would allow for the establishment of practical compromises. This would involve going trough the justifications associated with the three common goods in the process of finding solutions to collective action problems that could then be progressively institutionalized in semi-permanent arrangements. Sometimes the various values in presence have to be weighted against each other; in other cases, a consensus may be reached by identifying the norms or values that apply in the circumstances at hand. However, the compromises arrived at are never definitively settled; they are always subject to re-examination (Thévenot, 1989).

The solutions proposed by mainstream and new institutional economics, exposed in Section 2, take (long-term) self-interest as the sole motive for cooperation. They fail to recognize that, apart from the instrumental motives that workers hold, joint endeavours provide highly valued relational satisfaction and are deeply permeated by moral norms. Thus, the 'incentive-compatible devices', put forward by agency theories, and the command-and-control hierarchical structures, put forward by transaction-cost theories, cannot be but partial - and sometimes counterproductive - solutions. Work organizations may be better conceived as composed of communicative agents involved in collective action endeavours:

The term organization refers to the complex pattern of communications and other relations in a group of human beings. This pattern provides to each member of the group much of the information, assumptions, goals and attitudes that enter into their decisions, and provides him with a set of stable and 
comprehensible expectations as to what the other members of the group are doing and how they will react to what he says and does. (Simon, 1957: xvi)

A main function of management hence lies in the setting up of organizational forms and channels of communication that provide the conditions for communicative action..$^{15}$ They must allow discussion of the situation at hand, the goals to be pursued, and the evaluation criteria - within work teams, between work units, and between workers and supervisors. Communication is not only a vehicle of information; it is also a means to 'commonalize' things and allow actors to agree on, account for, and justify their actions.

Experimental work actually shows that cooperative behaviour may be elicited by promoting both social proximity between subjects and participation in decision-making processes (Frey and Bohnet, 1995). A large body of empirical studies now also robustly show that cooperation is determined by the workers' perceptions of procedural justice on the part of the organization and their supervisors (Tyler and Blader, 2000). Two criteria have proven crucial in influencing workers' perception of procedural justice: whether the organization gives the employee 'voice', i.e. an opportunity to state their side of the case; and whether the organization or the supervisor explains and justify their acts and decisions (Rotemberg, 2006). There thus seems to be overwhelming evidence that relational and moral considerations are significantly correlated with cooperation.

Barnard (1938) took, a long time ago, the 'functions of the executive' to entail a moral character. His conception of organizations as 'systems of cooperative services of persons' led him to highlight the conditions for collective action. He endorsed the view that the 'moral element', required for effective cooperation in organizations, is subject to moral justification and collectively supported through communication. Contrary to recent contributions (e.g. Casson, 1991), however, he did not view managers' moral function as a manipulative one. The conflicts of values that characterize all organizations constitute a serious personal and organizational issue, which may result in moral deterioration, erosion of the sense of responsibility, or withdrawal. 'Moral creativeness' on the part of managers would consist in the invention of a basis for the resolution of moral conflicts by introducing new forms of action that avoided conflict or by providing moral justification for exceptions or compromises.

Hence, apart from the solutions usually advanced in the economic literature, the collective action problem is tackled by nurturing an organizational environment that promotes the formation of common goods. Indeed, an important aspect of relational goods that should be taken into account is that 'the desired amounts and varieties of such goods cannot be efficiently secured through exchange nor command' (Gui, 2000: 154). The production of relational

15 It must be kept in mind that an 'ideal-speech' situation, i.e. undistorted communication required for communicative action, can never be guaranteed in workplace environments. In this regard, it is also worth reminding that about $80 \%$ of a manager's time is dedicated to communicating. 
goods can be promoted by providing the conditions favourable to satisfactory personal interactions and by activating non-egoistic motivations which are 'like catalysts in a chemical process' (157).

But rich social environments and a high reliability in interpersonal interactions may make the organization more vulnerable to the dynamic of these interactions, ${ }^{16}$ which are not controllable by either incentives or command. Opportunities to collective as well as interpersonal questioning and expression are forcefully needed if these perverse effects are to be hindered.

What actually is at stake with the promotion of the third common good is an emancipation project within work organizations. There are now many management proposals on organizational alternative ways of addressing the nature of coordination and the degree to which employees are expected to participate in decisions. But despite the spirit of the proponents, these discourses and practices are more often than not used to perpetuate oppression in the name of overcoming it (Alvesson and Willmont, 1992). In some cases, systems of 'employee voicing' and high degrees of normative control are implemented in order to avoid unionization and to create illusory 'communities' that bind 'employees' hearts and minds to the corporate interest' (quoted in Bamberger and Meshoulan, 2000: 144). Corporate culture, defined as the building of shared values that aim at the homogenization of preferences, is presented as a means to enhance the effectiveness of cooperation (Milgrom and Roberts, 1992), but it may instead result in some form of organizational tyranny.

Whether the existence of union voice is required by the imperative of justification and communicative action is not the subject of concern of this paper. It is nonetheless clear that the analytical propositions endorsed here call for some change in the functions conventionally assigned to management. It is implied that the accountability of managers extends beyond the owners of private corporations to their subordinates. Caught between contradictory demands and pressures, managers actually experience ethical problems, they run the risk of dismissal, and are 'victims' as well as perpetrators of discourses and practices that constrain their ways of thinking and acting (Alvesson and Willmont, 1992). The central problem of management resides in the social relations of production which systematically foster and sustain very limited and often distorted forms of communication between those occupying positions within the horizontal and vertical divisions of labour.

It has been recalled in Section 2 that the present production processes require high degrees of cooperation and voluntary contributions of effort. This progressively led management to boost workers' involvement and participation. But the flip side of increased commitment, empowerment, and organizational identification is a greater personal accountability, time pressure, and intensified systems of appraisal. Self-surveillance and enhanced work ethic substituted for 
Table 2. Devices and arrangements amenable to foster the three common goods

\begin{tabular}{ll}
\hline \hline Common goods & Management devices and organizational arrangements \\
\hline Common goals & - Incentive-compatible devices \\
& - Long and non-termed employment contracts that allow repeated \\
& interactions and reputation building \\
& - Monitoring arrangements (sanctions and punishment devices) \\
Relational satisfaction & - Teamwork or identification of work units \\
& - Promotion of the quality of work relations; opportunity to socialize \\
& - Opportunity to identify, express, and cultivate interpersonal ties \\
Moral norms and values & - Participation in decision-making through collective discussion of objectives \\
& and evaluation criteria \\
& - Opportunity to justify decisions (ability to identify and express intentions): \\
& top-down and bottom-up as well as horizontal communication channels \\
& - 'Moral creativeness' on the part of managers \\
\hline \hline
\end{tabular}

more conventional disciplinary control, ${ }^{17}$ and this is particularly relevant for managers. In parallel, increased competition at the global level and advances in information technology are now working in a direction opposite to that advocated in Table 2: they tend to augment worker and firm mobility and to reduce the duration of employment relations. Employment precariousness in turn tends to lessen workers' loyalty towards firms, prevent the nurturing of personal interactions and mutual commitments, and hinders workers' participation in decision-making and representative instances. The essential ingredients for cooperation are summarized in Table 2.

\section{Conclusions and directions for future research}

We argued that cooperation is supported by the presence of three common goods - common goals, relational satisfaction, and moral norms and values that are associated with three different sets of motives and behavioural rules. We noted that the reasons for cooperating evoke both instrumental and normative considerations since cooperation constitutes an instance of strategic and communicative action.

The framework put forward is still very tentative and should be refined in future research. The claims made call for additional analytical investigation and their normative implications should be further elaborated. Nonetheless, the arguments and evidence provided all point to the relevance of discriminating between the three common goods, sets of motives and rules. This clarification not only improves our understanding of cooperative behavior, but it also provides a more focused guide to help promote cooperation. It does so by highlighting the differentiated ways by which the heterogeneous motives may be activated for

17 In this perspective, worker participation programmes, for example, can induce work groups to move from interest solidarity to self- and hetero-surveillance. As is unavoidably the case, the practices suggested here can also have their perverse effects. 
cooperative action to take place. Finally, the critical role of communication in promoting each kind of common good was highlighted. Though the research is still incipient, a prolific agenda can already be identified.

The introduction of the notion of common goods in the analysis of cooperation has obvious connections with other research agendas that space constraints did not allow us to explore here. We can at least identify two obvious research programmes whose cross-fertilization with the common goods perspective seems most fruitful - the examination of the endogenous vs exogenous character of the preferences and rules that drive agents' behaviour and the analysis of the role of social identity in economic behaviour.

As was patent, the normative implications of the common goods framework is precisely to learn how to bring about and nurture the right kind of motivational factors ('preferences') and rules that promote and sustain cooperation. The question of how are social norms constructed and enforced is a much-discussed issue in new institutional economics. A recent strand of literature views social norms as endogenous equilibrium outcomes of social interactions (see Aoki, 2007). The enforceability issue is solved by assuming that agents' action plans and beliefs may become mutually consistent and their repeated implementation makes them sustainable/enforceable. No room is made for communication in this strand of literature, which implicitly deals with silent rather than communicative agents. The view presented here argues that social and moral norms are only partially endogenous and that their sustainability requires and relies on the level and scope of communication within organizations.

The analysis of identity in economics (Akerlof and Kranton, 2000, 2005; Davis, 2007) is another case of possible fruitful articulation with a common goods approach. Individuals' personal and social identities include social categories that explain individuals' behaviours, such as abidance by social and moral norms. Committing to and subsequently abiding by moral norms and virtues might be explained by their identity-conferring character (Minkler and Miceli, 2004). The formation of identity, personal and social, can hence contribute to and translate into the pursuit of common goods.

The result of these and other research agendas could expectedly feed into the common goods framework and integrate other common sets of motives that together enrich the conception of action and behaviour in economics.

The framework presented should be further elaborated with available empirical work and, hopefully, inspire research that further investigates and distinguishes the relative relevance and effectiveness of the various common goods, their conflicts and complementarities. Laboratory and field experiments are particularly adequate. In fact, they have already identified the role of social and moral norms in fostering cooperation and the critical importance of communication in this regard. The experiment carried out by Mohlin and Johannesson (2008), designed to evaluate the effect of communication on generosity in a dictator game and to separate the effect of the content of the communication from the 'relationship effect', seems to go in this direction. 
The limited external validity of experimental results demands having recourse to qualitative empirical methods not yet very familiar to economists. Of particular relevance to the common goods perspective would then be the study of cooperation within specific organizational arrangements and employment practices. Previous studies on worker attitudes, motivations, and commitments based on survey methods have already proven especially fruitful (Minkler, 2004). But they have not addressed how the institutional background interacts with individual motivations. Critical ethnographic work, in particular, could show how much more than instrumental action takes place in ordinary practice and in what ways normative claims are actually made, silenced, or reinforced.

To the extent that cooperation is crucial for efficiency and innovation in the present economic conditions, the creation of the institutional arrangements that may foster it - namely, the enhancement of democracy in work organizations should be seriously taken into account. This is not to mention the three virtues of democracy: its intrinsic importance, its instrumental contribution, and its constructive role in the creation of values and norms (Sen, 1999). Normative recommendations may ensue for managers: instead of acting as stockholders' agents, they might endorse the role of leaders of a community, seeking compromises between multiple claims and constantly reshaping the rules of the game in order to better accommodate conflicting demands.

\section{References}

Akerlof, G. (1982), 'Labor Contracts as Partial Gift Exchange', Quarterly Journal of Economics, 97: 543-69.

Akerlof, G. and R. Kranton (2000), 'Economics and Identity', Quarterly Journal of Economics, 105(3): 715-53.

Akerlof, G. and R. Kranton (2005), 'Identity and the Economics of Organization', Journal of Economic Perspectives, 19(1): 9-32.

Alchian, A. and H. Demsetz (1972), 'Production, Information Costs and Economic Organization', American Economic Review, 62(5): 777-795.

Alvesson, M. and H. Willmott (1992), Critical Management Studies, London: Sage Publications.

Anderson, E. (1990), 'The Ethical Limitations of the Market', Economics and Philosophy, 6: 179-205.

Aoki, M. (2007), 'Endogenizing Institutions and Institutional Changes', Journal of Institutional Economics, 3(1): 1-31.

Baker, G., R. Gibbons, and K. Murphy (2002), 'Relational Contracts and the Theory of the Firm', Quartely Journal of Economics, 117(1): 39-84.

Bamberger, P. and I. Meshoulan (2000), Human Resource Strategy - Formulation, Implementation and Impact, California: Sage Publications.

Barnard, C. (1938), The Functions of the Executive, Cambridge, MA: Harvard University Press.

Baron, J. N. and D. Kreps (1999), Strategic Human Resources: Frameworks for General Managers, Willey Press.

Becker, M. C. (2004), 'Organizational Routines: A Review of the Literature', Industrial and Corporate Change, 13(4): 643-678. 
Bewley, T. (1995), ‘A Depressed Labour Market as Explained by Participants', American Economic Review, Paper and Proceedings, 85: 250-254.

Casson, M. (1991), The Economics of Business Culture, Oxford: Clarendon.

Coase, R. (1937), 'The Nature of the Firm', Economica, 4(16): 386-405.

Cyert, M. R. and March J. G. (1963), A Behavioural Theory of the Firm, Englewood Cliffs, NJ: Prentice-Hall.

Davis, J. (2007), 'Akerlof and Kranton on Identity in Economic Theory', Cambridge Journal of Economics, 31(3): 349-362.

Demsetz, H. (1995), The Economics of the Business Firm: Seven Critical Commentaries, Cambridge, MA: Cambridge University Press.

Durkheim, É. (1984[1893]), The Division of Labour in Society, London: Macmillan.

Elster, J. (1985), 'Rationality, Morality, and Collective Action', Ethics, 96: 136-155.

Falk, A., E. Fehr, and U. Fishbacher (2003), 'On the Nature of Fair Behaviour', Economic Inquiry, 41(1): 20-26.

Fehr, E. and A. Falk (2002), 'Psychological Foundations of Incentives', European Economic Review, 46: 687-724.

Fehr, E. and U. Fischbacher (2003), 'The Nature of Human Altruism', Nature, 425(6960): 785-792.

Fehr, E. and S. Gächter (1998), 'How Effective Are Trust- and Reciprocity-Based Incentives?', in A. Ben-Ner and L. Putterman (eds.), Economics, Values and Organizations, Cambridge: Cambridge University Press, pp. 337-363.

Fehr, E. and S. Gächter (2000), 'Fairness and Retaliation: The Economics of Reciprocity', Journal of Economic Perspectives, 14(3): 159-181.

Frey, B. and I. Bohnet (1995), 'Institutions Affect Fairness - Experimental Investigations', Journal of Institutional and Theoretical Economics, 151(2): 286-303.

Grossman, S. and O. Hart (1986), 'The Costs and Benefits of Ownership: A Theory of Vertical and Lateral Integration', Journal of Political Economy, 94(4): 691-719.

Gui, B. (2000), 'Beyond Transactions: On the Interpersonal Dimensions of Economic Reality', Annals of Public and Cooperative Economics, 71(2): 139-169.

Gui, B. (2005), 'From Transactions to Encounters: The Joint Generation of Relational Goods and Conventional Values', in B. Gui and R. Sugden (eds.), Economics and Social Interactions: Accounting for Interpersonal Relations, Cambridge: Cambridge University Press.

Habermas, J. (1973), 'Travail et interaction', in La technique et la science comme idéologie, Paris: Gallimard.

Habermas, J. (1984), The Theory of Communicative Action, Vol. 1: Reason and the Rationalization of Society, Boston, MA: Beacon Press.

Hobbes, T. (1968), Leviathan, Baltimore: Penguin.

Jensen, M. C. and W. H. Meckling (1976), 'Theory of the Firm: Managerial Behavior, Agency Costs, and Ownership Structure', Journal of Finance, 3: 305-360.

Ledyard, J. (1995), 'Public Goods: A Survey of Experimental Research', in J. H. Roth and A. E. Kagel (eds.), The Handbook of Experimental Economics, Princeton, NJ: Princeton University Press.

Lopes, H. and Caldas, J. (2008), 'Firms: Collective Action and Its Supportive Values', in J. Davis and W. Dolfsma (eds.), The Elgar Companion to Social Economics, Cheltenham: Edward Elgar.

Lutz, M. (1999), Economics for the Common Good: Two Centuries of Economic Thought in the Humanistic Tradition, London: Routledge.

Milgrom, P. and J. Roberts (1992), Economics, Organization and Management, Prentice Hall. 
Minkler, L. (2004), 'Shirking and Motivations in Firms: Survey Evidence on Worker Attitudes', International Journal of Industrial Organization, 22: 863-884.

Minkler, L. and T. Miceli (2004), 'Lying, Integrity and Cooperation', Review of Social Economy, 62(1): 27-50.

Mohlin, E. and M. Johannesson (2008), 'Communication: Content or Relationship?', Journal of Economic Behavior and Organization, 65 (3-4): 409-419.

Nelson, J. (2001), 'The Separative Firm: Androcentric Bias and Business Ethics', Process Perspectives, 24(3). [Online] Available at: http://www.ctr4process.org/publications/ SeminarPapers/243Nelson.rtf [Accessed 20 October 2008].

Nelson, R. and S. Winter (1982), An Evolutionary Theory of the Economic Change, Cambridge, MA: Harvard University Press.

Nonaka, I., R. Toyama, and A. Nagata (2000), 'A Firm as Knowledge-creating Entity: A New Perspective on the Theory of the Firm', Industrial and Corporate Change, 9: 1-20.

Olson, M. (1971), 'The Logic of Collective Action: Public Goods and the Theory of Groups', Cambridge, MA: Harvard University Press.

Ostrom, E. (2000), 'A Behavioural Approach to the Rational Choice Theory of Collective Action', American Political Science Review, 92(1): 1-22.

Ostrom, E. (2007), 'Challenges and Growth: The Development of the Interdisciplinary Field of Institutional Analysis', Journal of Institutional Economics, 3(3): 239-264.

Pareto, V. (1909[1968]), 'Manuel d'Économie Politique (Ophélimité)', in A. N. Page (1968), Utility Theory: A Book of Readings, New York: John Wiley \& Sons.

Rob, R. and P. Zemsky (2002), 'Social Capital, Corporate Culture, and Incentive Intensity', RAND Journal of Economics, 33(2): 243-257.

Rotemberg, J. (2006), 'Altruism, Reciprocity and Cooperation in the Workplace', in S. C. Kolm and J. Mercier (eds.), Handbook of the Economics of Giving, Altruism and Reciprocity, North-Holland, Amsterdam: Elsevier, 1: 1371-1407.

Sally, D. (1995), 'Conversation and Cooperation in Social Dilemmas: A Meta-Analysis of Experiments from 1958-1992', Rationality and Society, 7: 58-92.

Samuelson, P. (1938), 'A Note on the Pure Theory of Consumer's Behaviour', Economica, 5(5): 61-71.

Searle, J. (2001), Rationality in action, Cambridge, MA: MIT Press.

Searle, J. (2005), 'What is an institution?', Journal of Institutional Economics, 1(1): 1-22.

Sen, A. (1967), 'Isolation, Assurance and the Social Rate of Discount', Quarterly Journal of Economics, 81: 112-124.

Sen, A. (1973), 'Behaviour and the Concept of Preference', Economica, 40: 241-259.

Sen, A. (1977), Development as Freedom, Oxford: Oxford University Press.

Sen, A. (1990), 'Rational Fools: A Critique of the Behavioral Foundation of Economics', Philosophy and Public Affairs, 6(4): 317-344.

Simon, H. (1957), Models of Man, New York: John Wiley \& Sons.

Sunstein, C. and E. Ullmann-Margalit (2001), 'Solidarity Goods', The Journal of Political Philosophy, 9(2): 129-149.

Thévenot, L. (1989), 'Équilibre et rationalité dans un univers complexe', Revue économique, 2: 147-197.

Tyler, T. and S. Blader (2000). Cooperation in Groups - Procedural Justice, Social Identity, and Behavioural Engagement, Philadelphia, PY: Psychology Press, Taylor \& Francis.

Walzer, M. (1983), Spheres of Justice: A Defence of Pluralism and Equality, Oxford: Blackwell.

Williamson, O. (2005), 'The Economics of Governance', AEA Papers and Proceedings, May 2005. 